\title{
Influence of Carotid Denervation on the Arousal and Cardiopulmonary Response to Rapidly Developing Hypoxemia in Lambs
}

\author{
JAMES E. FEWELL,' COLLEEN S. KONDO, VICTOR DASCALU, AND SONYA C. FILYK \\ Reproductive Medicine Research Group, Departments of Obstetrics and Gynaecology, Medical Physiology and \\ Paediatrics, University of Calgary, Health Sciences Centre, 3330 Hospital Drive, N.W., \\ Calgary, Alberta T2N 4NI, Canada
}

\begin{abstract}
Experiments were done on five lambs to determine if carotid denervation influences the arousal and cardiopulmonary responses to rapidly developing hypoxemia during sleep. Each lamb was anesthetized and instrumented for recordings of electrocorticogram, electrooculogram, nuchal and diaphragm electromyograms, and measurements of arterial blood pressure and arterial hemoglobin oxygen saturation. The carotid chemoreceptors and baroreceptors were denervated, a tracheostomy was done, and a fenestrated tracheostomy tube was placed in the trachea so that the inspired oxygen mixture could be changed quickly. No sooner than $3 \mathrm{~d}$ after surgery, measurements were made in quiet sleep and active sleep during control periods when the animal was breathing $21 \%$ oxygen and during experimental periods of rapidly developing hypoxemia when the animal was breathing 5\% oxygen. Rapidly developing hypoxemia was terminated during each epoch by changing the inspired gas mixture back to $21 \%$ oxygen once the animal aroused from sleep or once the arterial $\mathbf{H b}$ oxygen saturation decreased to $30 \%$. Arousal occurred during only 4 of 11 epochs in quiet sleep and during only 3 of 14 epochs in active sleep before the arterial $\mathrm{Hb}$ oxygen saturation decreased to $30 \%$. These data provide evidence that the carotid chemoreceptors and/or carotid baroreceptors play a major role in causing arousal from sleep during rapidly developing hypoxemia in lambs. (Pediatr Res 25: 473-477, 1989)
\end{abstract}

The arousal response is an important protective response that may prevent severe hypoxemia and death during sleep (1). Hypoxemia may occur during sleep in individuals with chronic lung disease (e.g. cystic fibrosis [2], bronchopulmonary dysplasia [3], asthma [4]) and/or during central or obstructive apnea. The usual respiratory response to hypoxemia is an increase in ventilation, which tends to increase the alveolar and arterial oxygen tension. However, as the ventilatory response to hypoxemia is decreased during active sleep compared to quiet sleep in lambs (5) and calves (6) (i.e. species that develop rib-cage paradox during active sleep) and the resumption of tidal ventilation

Received August 19, 1988; accepted January 5, 1989.

Correspondence and request for reprints James E. Fewell, Ph.D., Department of Obstetrics and Gynaecology and Medical Physiology, University of Calgary, Heritage Medical Research Building, 3330 Hospital Drive, N.W., Calgary, Alberta T2N 4NI, Canada.

Supported by U.S. Public Health Service Grants HL34377, HD24018, The Alberta Heritage Foundation for Medical Research, and The Christie Unit for the Study of Human Reproduction.

' J.E.F. is an Established Investigator of the American Heart Association and a Heritage Medical Scholar of the Alberta Heritage Foundation for Medical Research. during obstructive apnea is usually preceded by arousal $(7-10)$, the arousal response may be the most important response to hypoxemia during sleep.

Previous experiments on young lambs $(5,11-13)$ and calves (6) have demonstrated that arousal occurs from both quiet sleep and active sleep in response to alveolar hypoxia, but the mechanism remains unclear. The purpose of the present experiments was to investigate the effect of carotid-denervation on the arousal response from sleep to rapidly developing hypoxemia in young lambs.

\section{MATERIALS AND METHODS}

Five lambs ranging in age from 11 to $24 \mathrm{~d}$ were studied. Each lamb was separated from its ewe 3 to $7 \mathrm{~d}$ after birth and was housed in our laboratory in a Plexiglas cage with continuous access to milk (Lamb Milk Replacer, Land O'Lakes, Inc., Fort Dodge, IA). The lambs were among other lambs, fed and slept ad libitum, and soon became accustomed to the surroundings and laboratory personnel.

Surgical preparation. Each lamb underwent one operation before the study. For surgery, each lamb was given atropine sulfate $(0.2 \mathrm{mg} / \mathrm{kg}$ subcutaneously); anesthesia was induced by having the lamb breath 3 to $4 \%$ halothane in oxygen via a mask. The trachea was then intubated with a cuffed endotracheal tube; anesthesia was maintained by ventilating the lamb's lungs with $0.5-1.0 \%$ halothane in oxygen. An ECG, end-tidal carbon dioxide levels, and rectal temperature were monitored during surgery; body temperature was kept near $39^{\circ} \mathrm{C}$ with a heating pad, and end-tidal carbon dioxide levels were kept near $5 \%$ with a volumecycled ventilator.

The operation was done when the lambs were between 7 and $21 \mathrm{~d}$ of age. A double-lumen fiberoptic catheter oximeter (Model U440 Opticath, Oximetrix, Inc., Mountain View, CA; $90 \%$ response to a step change in $\mathrm{SaO}_{2}$ within $5 \mathrm{~s}$ ) was inserted to the thoracic aorta via a femoral artery for continuous measurement of arterial $\mathrm{Hb}$ oxygen saturation and blood pressure. Electrodes for the following recordings were also implanted: electrocorticogram (recorded from electrodes placed through burr holes to lie over the parietal cortex), electro-oculogram (recorded from electrodes placed at the inner and outer canthus of the right eye), nuchal electromyogram (recorded from electrodes placed in the dorsal cervical musculature) and diaphragm electromyogram (recorded from electrodes placed transabdominally into muscle fibers adjacent to the lateral margin of the central tendon of the right hemidiaphragm). A reference wire was sutured into the subcutaneous tissue of the scalp. The electrodes were made in our laboratory and were paired, Teflon-coated, multistranded stainless steel wires (AS 633, Cooner Wire Co., Chatsworth, CA); approximately $3 \mathrm{~mm}$ of the tip of each was bared and implanted. 
The proximal end of each wire was bared and soldered to the appropriate pin of an 18-pin electrical plug, which was interfaced with four differential high-impedance probes (7HIP5G, Grass Medical Instruments, Quincy, MA) during a study.

Carotid denervation was performed as follows: The carotid body and carotid sinus was approached as described by Appleton and Waites (14) and denervated as described by Bureau et al. (15). Briefly, the denervation procedure consisted of I) cutting the sinus nerve, 2) stripping the adventitia from the wall of the carotid artery from the origin of the lingual artery to $0.5 \mathrm{~cm}$ below the origin of the occipital artery, 3) removing all fibroadipose nodular tissue from around the occipital-carotid artery junction, 4) sectioning all minute vessels arising in the area of the carotid and occipital artery bifurcation, 5) stripping the adventitia from the wall of the occipital artery for $1 \mathrm{~cm}$ from its origin from the carotid artery, and 6) painting the walls of the stripped vessels with $7 \%$ phenol.

A tracheotomy was also performed, and a fenestrated tracheostomy tube (Shiley, Inc., Irvine, CA) was placed in the trachea. This tracheostomy tube allows one to select whether an animal breathes entirely through the opening of the tracheostomy tube (cuff inflated, inner cannula in place) or breathes entirely through its upper airway (cuff inflated, decannulation cannula in place). After surgery, the decannulation cannula was inserted into the tracheostomy tube so that airflow during tidal respiration would be through the upper airway. The lambs were allowed to recover from surgery in a Shor-Line intensive care unit for small animals (Schroer Manufacturing Company, Kansas City, MO) and were then placed back in their Plexiglas study cage in our sleep laboratory but were not studied before the 3rd postoperative day. The lambs received antibiotics daily, (penicillin $\mathrm{G}$ and dihydrostreptomycin) beginning on the day of surgery.

Conditions of observations. Our sleep laboratory consists of a large room containing two sound-attenuating chambers. Temperature, sound, and lighting can be precisely controlled in each chamber. The lambs in this series of experiments were raised in an environmental temperature of $25 \pm 1^{\circ} \mathrm{C}$. Each chamber also has a 1 -way viewing mirror as well as a closed circuit video system to observe the lambs. Before a study, a partition is placed in the cage to prevent the lamb from turning around once the catheter, electrode, and breathing circuit are connected. However, the lamb can still lie down, stand up, and feed ad libitum.

For a study, the vascular catheter is connected to a strain gauge manometer (Gould P23ID, Gould, Inc., Oxnard, CA) using rigid pressure monitoring tubing, and the optical connector is connected to the optical module of the oximeter processor; the strain gauge manometer is placed at the approximate level of the heart when the animal is lying down. In vivo calibration of the fiberoptic catheter oximeter was done after the oxygen saturation of a sample of arterial blood was determined using a co-oximeter (Instrumentation Laboratories 282). The inner cannula is placed into the tracheostomy tube and a breathing circuit (Neonatal Ventilator Circuit, model 5302, Intec Medical Inc., Blue Springs, $\mathrm{MO}$ ) attached so that 10 liters/min of a known gas (i.e. $21 \%$ or $5 \% \mathrm{O}_{2}$ ) can be passed by the tracheostomy tube. The 18-pin electrical plug is connected to the differential high impedance probes; a heavy duty cable connects the differential high impedance probes to $\mathrm{AC}$ preamplifiers (model 7P5 Wide Band AC EEG Preamplifier, Grass Medical Instruments, Quincy, MA) in the adjacent room. The amplified activity from the electrocorticogram is full-wave rectified and then integrated (model 7P10 Polygraph Integrator, Grass Medical Instruments) to give a running record of the total accumulated area under the electrocortical waves (11). The tracing writes out a ramp function, the slope of which is directly proportional to the ongoing input activity.

The following electrophysiologic criteria were used to define behavioral state once the animal was lying down (11). During quiet wakefulness, the electrocorticogram shows a fast-wave, lowvoltage pattern; there are occasional eye movements, and there is tonic activity on the nuchal electromyogram. During quiet sleep, the electrocorticogram shows a slow-wave, high-voltage pattern; there are no eye movements and there is tonic activity on the nuchal electromyogram. During active sleep, the electrocorticogram shows a fast-wave, low-voltage pattern; there are rapid eye movements on the electro-oculogram; there is no activity on the nuchal electromyogram, and there are occasional fast ear, facial, and limb twitches. Each lamb was allowed to cycle through at least one epoch of quiet sleep before the experiment actually began so that we could determine the amplitude of the integrated electrocortical activity and set strict criteria for defining quiet sleep.

The following electrophysiologic criteria were used to define arousal from sleep. During quiet sleep, the point of arousal was determined by a change in the electrocorticogram from a highvoltage, slow-wave pattern to a low-voltage, fast-wave pattern with continued activity on the nuchal electromyogram (11). During active sleep, the point of arousal was determined by a return of tonic activity on the nuchal electromyogram with continued low-voltage, fast-wave activity on the electrocorticogram.

Experimental protocol. During a study, systemic arterial blood pressure, arterial $\mathrm{Hb}$ oxygen saturation, and the electrophysiologic signals were recorded on a Grass model 7 polygraph, and the lambs were monitored on a closed-circuit video system. Measurements were made during 30-s control periods when the lambs were breathing $21 \%$ oxygen and during experimental periods of rapidly developing hypoxemia when the lambs were breathing $5 \%$ oxygen. Hypoxemia was terminated during an experimental period by changing the inspired oxygen concentration to $21 \%$ once the animal aroused from sleep. If an animal did not arouse before the arterial $\mathrm{Hb}$ oxygen saturation decreased to $30 \%$, the inspired oxygen concentration was changed back to $21 \%$. Because the mean epoch lengths of quiet sleep and active sleep of chronically instrumented lambs during this age range are 6 to $7 \mathrm{~min}$ and 3 to $4 \mathrm{~min}$, respectively (Johnson P, unpublished work), control measurements were made approximately 2 to $3 \mathrm{~min}$ after the lamb entered quiet sleep and approximately $30 \mathrm{~s}$ after the lamb entered active sleep. Experiments began between 0800 and 1000 and continued until sufficient data were collected.

Statistical analysis. For every animal, we determined an average value for each variable during the control period and during the experimental period immediately preceding arousal from quiet sleep and active sleep. If an animal did not arouse before the arterial $\mathrm{Hb}$ oxygen saturation decreased to $30 \%$, the values obtained immediately preceding the development of an arterial oxygen $\mathrm{Hb}$ saturation of $30 \%$ were used. To analyze the data statistically, we performed a 2-factor ANOVA for repeated measures of the same variable to determine if state (quiet sleep versus active sleep) or period (control versus experimental) affected arterial $\mathrm{Hb}$ oxygen saturation, heart rate, systolic blood pressure, diastolic blood pressure, or respiratory frequency (16). If there was a significant difference, a Duncan's multiple comparison test was performed to determine which means were statistically different (34).

In addition, as arousal was delayed after carotid denervation, we determined an average value for each variable at $10-13$ s into the experimental period for quiet sleep and at $41-44 \mathrm{~s}$ into the experimental period for active sleep; $13 \pm 8 \mathrm{~s}$ and $44 \pm 15 \mathrm{~s}$ are the times (mean \pm SD) to arousal from quiet sleep and active sleep, respectively, during exposure to $5 \%$ oxygen in carotidintact young lambs (11). Data from these time periods allows us to compare the cardiorespiratory responses to alveolar hypoxia obtained from carotid-denervated lambs (present study) to those obtained from carotid-intact young lambs (previous study, Ref 11). We performed a 3-factor ANOVA for repeated measures of the same variable to determine if group (carotid-denervated versus carotid-intact), period (control versus experimental) or state (quiet sleep versus active sleep) affected heart rate, systolic blood pressure, diastolic blood pressure, or respiratory frequency 
(16). If there was a significant difference, a Duncan's multiple comparison test was performed to determine which means were statistically different (34).

\section{RESULTS}

Carotid denervation significantly influenced the arousal and cardiopulmonary responses to rapidly developing hypoxemia (Table 1, Fig. 1). Arousal occurred during only four of 11 epochs in quiet sleep and during only three of 14 epochs in active sleep before the arterial $\mathrm{Hb}$ oxygen saturation decreased to $30 \%$. This is in contrast to the response we have previously observed in carotid-intact lambs (11) where arousal occurred during 25 of 25 epochs in quiet sleep $\left(\mathrm{SaO}_{2} 80 \pm 5 \%\right.$ at arousal, mean $\left.\pm 1 \mathrm{SD}\right)$ and during 20 of 23 epochs in active sleep $\left(\mathrm{SaO}_{2} 55 \pm 11 \%\right.$ at arousal, mean $\pm 1 \mathrm{SD}$ ) before electrocortical signs of cerebral hypoxia developed.

Carotid denervation affected baseline cardiorespiratory variables. Systolic and diastolic blood pressure were increased in carotid-denervated lambs compared to carotid-intact lambs (Ref 11 , Table 2) in both quiet sleep and active sleep. However, heart rate was increased only during quiet sleep in carotid-denervated lambs compared to carotid-intact lambs. Arterial blood gases and $\mathrm{pH}$ during quiet wakefulness were as follows: $\mathrm{pH}, 7.37 \pm$ $0.02 ; \mathrm{PaO}_{2}, 67 \pm 10$ torr; and $\mathrm{PaCO}_{2}, 54 \pm 2$ torr.

Carotid denervation also affected the cardiorespiratory response to rapidly developing hypoxemia (Table 2). Systolic and diastolic blood pressure and heart rate increased much more during active sleep in carotid-denervated lambs than in carotidintact lambs. In addition, carotid denervation eliminated the early respiratory frequency response to rapidly developing hypoxemia as compared to carotid-intact animals (Table 2 ).

\section{DISCUSSION}

Our study provides new information about the mechanism of arousal from sleep in response to cardiorespiratory stimuli in lambs. The data provide evidence that the carotid body and/or the carotid sinus plays a major role in causing arousal from sleep during rapidly developing hypoxemia. Furthermore, carotid denervation significantly affected baseline cardiorespiratory control as well as the cardiorespiratory response to rapidly developing hypoxemia.

Carotid denervation significantly affected the arousal response to rapidly developing hypoxemia. Arousal occurred during only four of 11 epochs in quiet sleep and during only three of 14 epochs in active sleep before the arterial $\mathrm{Hb}$ oxygen saturation decreased to $30 \%$. This is in marked contrast to what we have previously observed in carotid-intact lambs $(11-13)$. Although our data provide evidence that the carotid sinus and/or carotid body play a major role in causing arousal from sleep during rapidly developing hypoxemia, they do not provide definitive information about the factor(s) that actually initiate the response. There are several possibilities.

The first possibility is that arterial hypoxemia stimulates the carotid bodies which stimulate the recticular activating system (17) and cause arousal. The second possibility is that arterial hypoxemia stimulates the carotid bodies that produce an increase in ventilation and sensory input to the recticular activating system from the lungs and chest wall and cause arousal. In support of this, Bowes et al. have reported that bilateral vagal blockade delays the arousal response to rapidly developing hypoxemia in adult dogs (18). The third possibility is that arterial hypoxemia stimulates the carotid bodies, which produces an increase in heart rate and blood pressure and stimulates the carotid sinus baroreceptors, which causes arousal. We have previously reported that acute increases in blood pressure cause arousal from sleep in lambs, (19) and Horne et al. (20) recently reported that the arousal response to an acute increase in blood pressure is abolished by sinoaortic denervation in lambs.

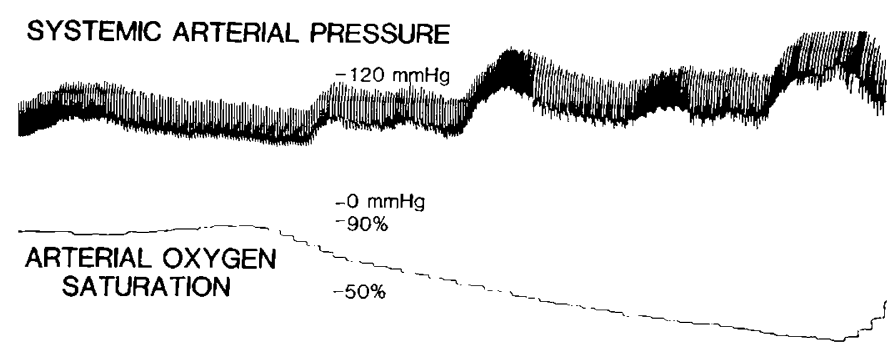

ELECTRO-OCULOGRAM

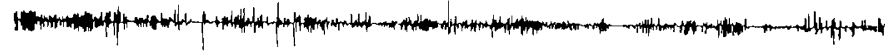

NUCHAL ELECTROMYOGRAM

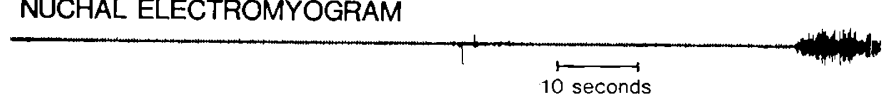

\section{DIAPHRAGM ELECTROMYOGRAM}

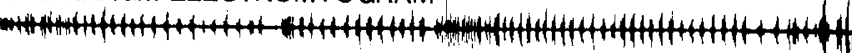

INTEGRATED DIAPHRAGM ELECTROMYOGRAM

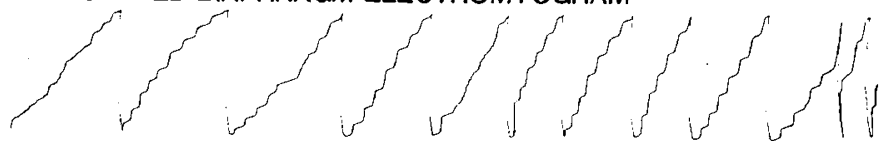

Fig. 1. Tracing showing variables during control period and during experimental period in one epoch of active sleep where animal did arouse in response to rapidly developing hypoxemia.

Table 1. Arousal and cardiorespiratory response to rapidly developing hypoxemia in carotid-denervated young lambs during quiet sleep and active sleep*

\begin{tabular}{|c|c|c|c|c|c|c|}
\hline \multirow[b]{2}{*}{ Variable } & \multicolumn{3}{|c|}{ Quiet sleep } & \multicolumn{3}{|c|}{ Active sleep } \\
\hline & $\begin{array}{c}\text { Control } \\
\text { period }\end{array}$ & & $\begin{array}{c}\text { Experimental } \\
\text { period }\end{array}$ & $\begin{array}{l}\text { Control } \\
\text { period }\end{array}$ & & $\begin{array}{c}\begin{array}{c}\text { Experimental } \\
\text { period }\end{array} \\
\end{array}$ \\
\hline $\mathrm{SaO}_{2}(\%)$ & $81 \pm 9$ & $\dagger$ & $37 \pm 3$ & $82 \pm 6$ & $\dagger$ & $32 \pm 4$ \\
\hline Heart rate (beats/min) & $\$ 189 \pm 26$ & $\ddagger$ & $193 \pm 39$ & $147 \pm 27$ & $\dagger$ & $179 \pm 29$ \\
\hline Systolic blood pressure (mm Hg) & $111 \pm 13$ & $\dagger$ & $149 \pm 15$ & $98 \pm 8$ & $\dagger$ & $142 \pm 15$ \\
\hline Diastolic blood pressure $(\mathrm{mm} \mathrm{Hg})$ & $70 \pm 7$ & $\dagger$ & $104 \pm 21$ & $53 \pm 13$ & $\dagger$ & $92 \pm 15$ \\
\hline Respiratory frequency (breaths/min) & $30 \pm 11$ & $\dagger$ & $41 \pm 13$ & $37 \pm 15$ & & $43 \pm 18$ \\
\hline
\end{tabular}

* Values are means $\pm 1 \mathrm{SD}$ for $n=5$. Measurements were made during the experimental period immediately preceding arousal; if arousal did not occur before a $\mathrm{SaO}_{2}$ of $30 \%$, measurements were made immediately preceding development of a $\mathrm{SaO}_{2}$ of $30 \%$. A value of $30 \%$ was used for $\mathrm{SaO}_{2}$ during the experimental period if arousal did not occur.

$\dagger p<0.05$ for control period vs. experimental period

$\ddagger p<0.05$ for quiet sleep $v s$. active sleep for a given period as determined by MANOVA and Duncan's multiple comparison test. 
Table 2. Comparison of cardiovascular and respiratory responses to rapidly developing hypoxemia in carotid-intact (I) and carotiddenervated (D) young lambs during quiet sleep and active sleep. ${ }^{*}$

\begin{tabular}{|c|c|c|c|c|c|c|c|}
\hline \multirow[b]{2}{*}{ Variable } & \multirow[b]{2}{*}{ Group } & \multicolumn{3}{|c|}{ Quiet sleep } & \multicolumn{3}{|c|}{ Active sleep } \\
\hline & & $\begin{array}{l}\text { Control } \\
\text { period }\end{array}$ & & $10-13 \mathrm{~s}$ & $\begin{array}{l}\text { Control } \\
\text { period }\end{array}$ & & $41-43 s$ \\
\hline Heart rate (beats $/ \mathrm{min}$ ) & I & $\begin{array}{c}162 \pm 22 \\
\ddagger \\
189 \pm 26\end{array}$ & $\dagger$ & $\begin{array}{c}174 \pm 28 \\
\pm \\
202 \pm 30\end{array}$ & $\begin{array}{l}153 \pm 25 \\
147 \pm 27\end{array}$ & $\dagger$ & $\begin{array}{c}146 \pm 23 \\
\ddagger \\
188 \pm 42\end{array}$ \\
\hline Systolic blood pressure $(\mathrm{mmHg})$ & I & $\begin{array}{c}82 \pm 9 \\
\ddagger \\
111 \pm 13\end{array}$ & & $\begin{array}{c}86 \pm 11 \\
\ddagger \\
117 \pm 14\end{array}$ & $\begin{array}{c}73 \pm 12 \\
\ddagger \\
98 \pm 8\end{array}$ & $\dagger$ & $\begin{array}{c}83 \pm 9 \\
+ \\
128 \pm 27\end{array}$ \\
\hline Diastolic blood pressure $(\mathrm{mmHg})$ & $\begin{array}{l}\mathrm{I} \\
\mathrm{D}\end{array}$ & $\begin{array}{c}57 \pm 5 \\
\pm \\
70 \pm 7\end{array}$ & & $\begin{array}{c}60 \pm 7 \\
\pm \\
78 \pm 10\end{array}$ & $\begin{array}{l}48 \pm 14 \\
53 \pm 13\end{array}$ & $\dagger$ & $\begin{array}{c}52 \pm 7 \\
\stackrel{\ddagger}{\ddagger} \\
80 \pm 30\end{array}$ \\
\hline Respiratory frequency (breaths/min) & $\mathrm{D}$ & $\begin{array}{l}25 \pm 5 \\
30 \pm 11\end{array}$ & $\dagger$ & $\begin{array}{l}39 \pm 11 \\
32 \pm 11\end{array}$ & $\begin{array}{l}39 \pm 10 \\
37 \pm 15\end{array}$ & $\dagger$ & $\begin{array}{c}56 \pm 10 \\
\stackrel{+}{ } \\
38 \pm 18\end{array}$ \\
\hline
\end{tabular}

* Values are means $\pm 1 \mathrm{SD} . n=8$ for carotid-intact animals (Ref. 11 ) and $n=5$ for carotid-denervated animals. Experimental measurements were made at $10-13 \mathrm{~s}$ in quiet sleep and $41-43 \mathrm{~s}$ in active sleep.

$\dagger p<0.05$ for control period $v s$. experimental period.

$\$ p<0.05$ for carotid-intact $v s$. carotid-denervated as determined by MANOVA and Duncan's multiple comparison test.

It is important to point out that our carotid denervation procedure, as well as the carotid denervation procedure of previous investigators $(18,21)$, not only eliminated afferents from the carotid chemoreceptors but also eliminated afferents from the carotid baroreceptors. The effectiveness of our carotid denervation procedure is provided by at least three lines of evidence. First, hypoventilation and hypoxemia were observed during resting conditions compared to intact animals (22). Second, the early respiratory frequency response to rapidly developing hypoxemia was eliminated as compared to intact animals (Table 2); the late respiratory frequency response to hypoxemia in carotid-denervated animals (Table 1) may have resulted from stimulation of the aortic chemoreceptors or from central stimulation as have previously been reported in adult cats (23). Third, systemic arterial hypertension was observed during resting conditions (Table 2).

Our experiments were done on lambs during the 2 nd or 3 rd wk of postnatal life. It is likely that the carotid chemoreceptors play a more important role in initiating the arousal response to rapidly developing hypoxemia during this period than during the immediate postnatal period, as Blanco et al. (24) have shown that carotid chemoreceptor activity-spontaneous or in response to a low $\mathrm{PaO}_{2}$-is minimal during the 1 st $\mathrm{d}$ or two of postnatal life. However, this requires further investigation.

Our results on the arousal response are in agreement with those of Bowes et al. (18), who found that carotid denervation had a profound effect on the arousal response to rapidly developing hypoxemia with arousal failing to occur despite arterial $\mathrm{Hb}$ oxygen saturations below $50 \%$ in adult dogs. Arousal occurred at arterial $\mathrm{Hb}$ oxygen saturations of $83 \pm 5 \%$ (mean \pm 1 $\mathrm{SE}$ ) and $71 \pm 2 \%$ in quiet sleep and active sleep, respectively, in carotid-intact dogs. However, our results do not agree with those of Neubauer et al. (21), who found that rapidly developing hypoxemia produced arousal in $46 \mathrm{~s}$ and at an arterial $\mathrm{Hb}$ oxygen saturation of $47 \pm 2 \%$ (mean $\pm \mathrm{SE}$ ) in carotid-intact adult cats and in $42 \mathrm{~s}$ and at an arterial $\mathrm{Hb}$ oxygen saturation of $50 \pm 2 \%$ in carotid-denervated cats during quiet sleep. However, one might speculate that the apparent discrepancy is related to the fact that Neubauer et al. performed experiments on sleep-deprived adult cats, and previous experiments by Bowes et al. (5) have provided evidence that short-term sleep fragmentation delays the arousal response to alveolar hypoxia in adult dogs.

The arousal response from sleep has been suggested to be an important protective response that may prevent severe hypox- emia and death during an apneic episode (1). Although apnea occurs to some extent in almost all preterm (26) and term infants (27), little is known about the mechanism that terminates an apneic episode. Read and Henderson-Smart (26) have observed that prolonged apnea (i.e. apnea of $20 \mathrm{~s}$ or more) occurs in the majority of babies under $30 \mathrm{wk}$ of gestation, in about $50 \%$ of babies at 30-32 wk of gestation, and in about $7 \%$ of babies at 34-35 wk of gestation. Furthermore, Southall et al. (28) have presented data showing that 34 of 50 (i.e. 68\%) randomly selected, healthy term infants studied between 1 and $15 \mathrm{~d}$ postnatally had apneic episodes of $10 \mathrm{~s}$ or greater and that the 95 th percentile extended up to $18 \mathrm{~s}$. Guntheroth $(28)$ has suggested that these infants do not die because of an intact arousal response and has hypothesized that the crucial area of abnormal physiology in the sudden infant death syndrome is arousal after apnea. The importance of the arousal response is at least 2-fold. First, wakefulness per se is a potent stimulus to breathing. Second, arousal permits the limitation of behavioral and a ventilatory response to the stimulus; arousal is generally thought to precede resumption of tidal ventilation during apnea $(7-10)$.

Two recent studies have provided evidence of an abnormal arousal response to hypoxemia in infants who have had an apparent life-threatening event $(30,31)$. McCulloch et al. (29) found that only one of 11 infants with an apparent life-threatening event aroused in response to progressive alveolar hypoxia $\left(\mathrm{FIO}_{2} \mathrm{0.15}\right)$ compared to 14 of 22 normal infants. After this study, it was suggested that the lack of an arousal response in $30 \%$ of the control infants was due to lack of maximal chemoreceptor stimulation (31). Subsequently, van der Hal (30) found that nine of nine control infants aroused in response to more pronounced alveolar hypoxia $\left(\mathrm{FIO}_{2} \mathrm{0.11}\right)$, compared to only 19 of 50 infants who had experienced an apparent life-threatening event. Although these data might support the hypothesis that an abnormal arousal response to hypoxemia plays a role in the final pathway to the sudden infant death syndrome, one also has to implicate failure of other "backup" mechanism(s) (e.g. gasping or circulatory failure), as these infants did not die (31). Recent evidence has been provided that the arousal response to alveolar hypoxia in some infants with bronchopulmonary dysplasia is delayed to the extent that some of the infants required vigorous stimulation and supplemental oxygen after the initial arousal response (32).

The results of our studies may have implications for the sudden infant death syndrome. If the final event is apnea, as has been hypothesized $(28,33)$, data from our previous studies would 
allow one to speculate that $l$ ) if the rate of change of arterial oxygen is great enough during apnea in active sleep, arousal may fail to occur before electrocortical signs of cerebral hypoxia and primary apnea occur (11); and that 2) if an infant is repeatedly exposed to hypoxemia-either as a result of multiple apneic episodes or hypoxemia during sleep as a result of gas exchange abnormalities - that the arousal response to apnea might be impaired (12). Furthermore, data from our present study would allow one to speculate that if carotid chemoreceptor and/or carotid baroreceptor function is impaired, arousal may fail to occur before hypoxic cerebral depression occurs. If, in addition, there is a deficit in the gasping mechanism or if the circulation fails before the onset of gasping, death could quickly ensue.

\section{REFERENCES}

1. Phillipson EA, Sullivan CE 1978 Arousal: the forgotten response to respiratory stimuli Am Rev Respir Dis 118:807-809

2. Muller NL, Francis PW, Gurwitz D, Levison H, Bryan AC 1980 Mechanism of hemoglobin desaturation during rapid-eye-movement sleep in normal subjects and in patients with cystic fibrosis. Am Rev Respir Dir 121:463469

3. Taussig LM: Long-term management and pulmonary prognosis in bronchopulmonary dysplasia. In: Farrell PM, Taussig LM (eds) Bronchopulmonary Dysplasia and Related Chronic Disorders, Ross Laboratories, Columbus, pp $126-135$

4. Hudgel DW, Kellum R, Martin RJ, Johnson B 1982 Depressed arousal response to airflow obstruction-A possible factor in near fatal nocturnal asthma. Am Rev Respir Dis 125:202

5. Henderson-Smart DJ, Read DJC 1979 Ventilatory responses to hypoxemia during sleep in the newborn. J Dev Physiol 1:195-208

6. Jeffery HE, Read DJC 1980 Ventilatory responses of newborn calves to progressive hypoxia in quiet and active sleep. J Appl Physiol 48:892-895

7. Gastaut H, Tassinari CA, Duron B 1966 Polygraphic study of the episodic diurnal and nocturnal (hypnic and respiratory) manifestations of the Pickwickian Syndrome. Brain Res 2:167-186

8. Walsh RE, Michaelson ED, Harkerload LE, Zichelboim A, Sackner MA 1972 Upper airway obstruction in obese patients with sleep disturbances and somnolence. Ann Intern Med 76:185-192

9. Remmers JE, DeGroot WJ, Sauerland EK, Anch AM 1978 Pathogenesis of upper airway occlusion during sleep. J Appl Physiol 44:931-938

10. Frank Y, Kravath RE, Pollak CP, Weitzman ED 1983 Obstructive sleep apnea and its therapy: Clinical and polysomnographic manifestations. Pediatrics 71:737-740

11. Fewell JE, Baker SB 1987 Arousal from sleep during rapidly developing hypoxemia in lambs. Pediatr Res 22:471-477

12. Fewell JE, Konduri GG 1988 Influence of repeated exposure to rapidly developing hypoxemia on the arousal and cardiopulmonary response to rapidly developing hypoxemia in lambs. $\mathrm{J}$ Dev Physiol in press

13. Fewell JE, Konduri GG 1988 Repeated exposure to rapidly developing hypoxemia influences the interaction between oxygen and carbon dioxide in initiating arousal from sleep in lambs. Pediatr Res 24:28-34

14. Appleton AB, Waites GMH 1957 A surgical approach to the superior cervical ganglion and related structures in the sheep. J Physiol (Lond) 135:52-57

15. Bureau MA, Lamarche $\mathbf{J}$, Foulon P, Dalle D 1985 Postnatal maturation of respiration in intact and carotid body-chemodenervated lambs. J Appl Physiol 59:869-874

16. Winer BJ 1971 Single-factor experiments having repeated measures on the same elements. In: Statistical Principles in Experimental Design, McGrawHill Book Company, New York, pp 261-308

17. Hugelin A, Bonvallet M, Dell P 1959 Activation reticulaire et corticale d'origine chemoreceptive au cours de l'hypoxie. Electroencephalogr Clin Neurophysiol 11:325-340

18. Bowes G, Townsend ER, Kozar LF, Bromley SM, Phillipson EA 1981 Effect of carotid body denervation on arousal response to hypoxia in sleeping dogs. J Appl Physiol 51:40-45

19. Fewell JE, Johnson P 1984 Acute increases in blood pressure cause arousal from sleep in lambs. Brain Res $311: 259-265$

20. Horne RSC, Berger PJ, de Preu N, Walker AM 1988 Arousal responses to hypertension in newborn lambs are abolished by sino-aortic denervation. Proceedings of the Society for the Study of Fetal Physiology, p24

21. Neubauer JA, Santiago TV, Edelman NH 1981 Hypoxic arousal in intact and carotid chemodenervated sleeping cats. J Appl Physiol 51:1294-1299

22. Fewell JE, Williams BJ, Hill DE 1984 Sleep does not affect the cardiovascular response to alveolar hypoxia in lambs. J Dev Physiol 6:401-405

23. Miller MJ, Tenney SM 1975 Hypoxia-induced tachypnea in carotid-deafferentiated cats. Respir Physiol 23:31-39

24. Blanco CE Dawes GS, Hanson MA McCooke HB 1984 The response to hypoxia of arterial chemoreceptors in fetal sheep and new-born lambs. J Physiol (Lond) 351:25-37

25. Bowes G, Woolf GM, Sullivan CE, Phillipson EA 1980 Effect of sleep fragmentation on ventilatory and arousal responses of sleeping dogs to respiratory stimuli. Am Rev Respir Dis 122:899-908

26. Read DJC, Henderson-Smart DJ 1984 Regulation of breathing in the newborn during different behavioral states. Annu Rev Physiol 46:675-685

27. Southall DP, Richards J, Brown DJ, Johnston PGB, DeSwiet M, Shinebourne EA 1980 24-hour recordings of ECG and respiration in the newborn infan with findings related to sudden death and unexplained brain damage in infancy. Arch Dis Child 55:7-16

28. Guntheroth WG 1983 Arrhythmia, apnea or arousal? In: Tildon WT, Rolder LM, Steinschneider A (eds) Sudden Infant Death Syndrome. Academic Press. London, pp 263-269

29. McCulloch K, Brouillette RT, Guzzetta AJ, Hunt CE 1982 Arousal responses in near-miss sudden infant death syndrome and in normal infants. J Pediatr 101:911-917

30. van der Hal AL, Rodriguez AM, Sargent CW, Platzker ACG, Keens TG 1985 Hypoxic and hypercapneic arousal responses and prediction of subsequent apnea in apnea of infancy. Pediatrics 75:848-854

31. Hunt CE, Brouillette RT 1987 Sudden infant death syndrome: 1987 perspective. J Pediatr 110:669-678

32. Garg M, Kurzner SI, Bautista D, Keens TG 1988 Hypoxic arousal responses in infants with bronchopulmonary dysplasia. Pediatrics 82:59-63

33. Steinschneider A 1972 Prolonged apnea and the sudden infant death syndrome: clinical and laboratory observations. Pediatrics 50:646-654

34. Zar JH 1979 Multiple comparisons. In: Biostatistical Analyses. Prentice-Hall, Englewood Cliffs, NJ, p. 151

\section{Erratum}

The article by Hirokazu Tsukahara et al. entitled "Insulin resistance in a boy with congenital generalized lipodystrophy" (Pediatr Res 24:668-672,1988) contained an error in an author's name. The correct spelling is Kazunori Yamada. The correct affiliation for authors H. Tsukahara, K. Kikuchi, H. Kuzuya, A. Kosaki, T. Kakehi, H. Nishimura, K. Yamada, Y. Yoshimasa, H. Imura, and H. Mikawa is Kyoto University School of Medicine. The printer regrets these errors. 